\title{
Characterization of Polypropylene Green Composites Reinforced by Cellulose Fibers Extracted from Rice Straw
}

\author{
Ngo Dinh Vu (i), Hang Thi Tran $(\mathbb{D}$, and Toan Duy Nguyen \\ Viet Tri University of Industry, No. 9, Tien Son, Tien Cat, Viet Tri, Phu Tho, Vietnam \\ Correspondence should be addressed to Hang Thi Tran; hangtt@vui.edu.vn
}

Received 23 August 2017; Accepted 1 March 2018; Published 4 April 2018

Academic Editor: Qinglin Wu

Copyright (C) 2018 Ngo Dinh Vu et al. This is an open access article distributed under the Creative Commons Attribution License, which permits unrestricted use, distribution, and reproduction in any medium, provided the original work is properly cited.

\begin{abstract}
Polypropylene (PP) based green composites containing 10, 20, 30, 40 and $50 \mathrm{wt} \%$ of cellulose fibers (CFs) which were extracted from rice straw were successfully prepared by melt blend method. The CFs washed with $\mathrm{H}_{2} \mathrm{O}_{2}$ after alkaline extraction showed lower water absorption than that not washed with $\mathrm{H}_{2} \mathrm{O}_{2}$. The thermal, mechanical, and biodegradation properties of composites were also investigated. The $10 \%$ weight loss temperature of the composites was decreased with the increasing CFs content, but all the composites showed over $300^{\circ} \mathrm{C}$. Young's modulus and flexural properties of PP were improved by blending PP with CFs. The pure PP showed no degradability, but the PP/CFs composites degraded from about 3 to $23 \mathrm{wt} \%$, depending on CFs content after being buried in soil for 50 days. These PP/CFs composites with high thermal, mechanical properties and biodegradability may be useful as green composite materials for various environmental fields.
\end{abstract}

\section{Introduction}

Natural fibers as reinforced materials in polymer composites have attracted much attention for being applicable in many fields such as automotive, aerospace, packaging, construction, and transportation industries [1-6]. Natural fibers which are used as fillers or reinforcement materials in polymer composites including palm sheath [7], palm leaf [8], guayule biomass [9], bagasse [10], sunflower stalk flour [11], banana [12], sugarcane, pineapple, ramie, and cotton [13] show many advantages such as renewability, biodegradability, $\mathrm{CO}_{2}$ neutrality, nontoxicity, wide availability, low cost, low density, low energy consumption during fabrication, and high specific strength compared to synthetic fibers [14-16]. Therefore, the polymer composites reinforced by natural fibers are becoming significantly important for the production of a large variety of composites due to being relatively cheap, lightweight, and eco-friendly materials [17].

The choice of polymer as a matrix material is important for the kinds of natural fiber reinforcement. Polyethylene, polystyrene, polyvinyl chloride, polylactides (PLAs), polypropylene (PP), and so on are thermoplastic materials and can be used as matrix materials for composites. PLAs are biodegradable polymers, are available from renewable sources, and degrade completely to water and carbon dioxide. However, the cost of PLAs is significantly higher than other polymers such as PP. Among the types of plastics, PP is widely used in the industrial products and household goods and especially as a matrix material in composites, due to low production cost, design flexibility, and recyclability, compared with other polymers. Several potential properties of PP include heat distortion temperature, flame retardant, transparency, and dimensional stability. Besides, PP also suits filling, reinforcing, and blending [12]. Therefore, many researches have reported composite materials with PP as a matrix and CFs of various plants as reinforcement materials $[12,18-22]$. CFs have a number of -OH groups and hence lead to a poor interaction between PP and CFs in composite material and even would decrease mechanical and thermal properties such as tensile strength, flexural strength, and thermal stability [23]. The problem can be solved by the modification of CFs surface using physical or chemical treatment methods. Chemical treatment methods are known as silane treatment, alkaline treatment, maleated coupling, acetylation, and enzyme treatment [24]. Akhtar et al. studied the mechanical properties of alkaline treated and untreated 
kenaf reinforced PP composite with fibers volume fractions of 10 to $50 \%$ [18]. The results were that PP composites with alkaline treated kenaf showed greater mechanical properties than alkaline untreated kenaf and composite with $40 \%$ of treated kenaf exhibited highest mechanical properties. The natural fibers are treated using alkaline, the lignin, hemicellulose, and oils and other substances on the fiber surface are removed, leading to the improvement of the bonding between the fiber and matrix [20]. In addition, moving them on the fiber surface increases the number reaction sites on the fiber surface and improves surface roughness of fibers [18, $25,26]$. The CFs treatment using alkaline not only increases mechanical properties of PP matrix composites but also contributes to other matrix composites. Ray et al. reported that the jute fibers which were treated using $5 \% \mathrm{NaOH}$ for 4,6 , and $8 \mathrm{~h}$ at $30^{\circ} \mathrm{C}$ increased their flexural modulus by 12,68 , and $79 \%$, respectively [27]. To date, some studies have reported to use wheat straw in polymer composites as a reinforcement material, and the matrix material in composites was commonly used as PP [28-31]. Zou et al. demonstrated that, for PP matrix composites, split wheat straw fibers showed better reinforcement material than whole wheat straw fibers, due to the increase in the surface area and aspect ratio of split configuration [31]. However, to the best of our knowledge, relatively little research is available on cellulose natural fibers from rice straw reinforced composite materials, especially no report in CFs from rice straw. In Vietnam, about 45 million tonnes of grains equivalent to 54 million tonnes of rice straw was produced in 2015, and it tends to increase in the coming years. However, most of the postharvest rice straw is burnt on open fields, causing ecological environment pollution and wasting potential resources. According to a survey by the Food and Agriculture Organization of the United Nations (FAO) in 2016, global paddy production reached 761.9 million tonnes, especially in Asia, which is set to lead the global recovery, with 680.1 million tonnes of grains being produced [32]. The agricultural wastes including rice straw are one of the most important problems that must be resolved for the conservation of global environment [33]. Therefore, research to convert them to useful materials is essential.

This study focuses on thermal and mechanical properties of composites consisting of PP and CFs which were extracted from rice straw using alkaline treatment method. Cellulose from rice straw is abundant in nature and contributes to environmental improvement due to its excellent biodegradable properties [34]. In this paper, the biodegradability of PP/CFs composites is also reported. This research is especially important in Asia in general and in Vietnam in particular. The results are expected to contribute to environmental protection and solve the problem of wasting resources.

\section{Materials and Methods}

2.1. Materials. Commercial PP used as a matrix material was purchased from the Polyolefin Co., Private Limited, Singapore, with melting temperature of $170^{\circ} \mathrm{C}$, density of $0.90 \mathrm{~g} \cdot \mathrm{cm}^{-3}$, and melt-flow index of $10 \mathrm{~g} /(10 \mathrm{~min})$ at $230^{\circ} \mathrm{C}$. Rice straw was collected from a rural area of Vietnam. The chemical composition of rice straw depends on the rice straw varieties, producing area, and so forth. It contains on average $32-47 \%$ cellulose, $19-32 \%$ hemicellulose, 5-24\% lignin, and 13-20\% other components [35-38]. The rice straw used in this study contained $39.20 \%$ cellulose, $19.02 \%$ lignin, $18.52 \%$ hemicellulose, $14,26 \%$ ash, and $9.18 \%$ other components. $\mathrm{NaOH}$ and $\mathrm{H}_{2} \mathrm{O}_{2}$ used in this work were supplied by SigmaAldrich Corporation.

2.2. CFs Extraction from Rice Straw. Alkaline treatment or mercerization is in the greatest popularity regarding chemical treatments of natural fibers to reinforce thermoplastics. In this study, CFs of rice straw were obtained using alkaline treatment method as follows. Rice straw was cut with dimension of about $2 \mathrm{~mm}$ using screen and then immersed in the $\mathrm{NaOH} 2 \mathrm{M}$ solution with the rate of solid/liquid of $1 / 10 \mathrm{~g} / \mathrm{ml}$ for $2 \mathrm{~h}$ at $90^{\circ} \mathrm{C}$ below stirring speed of $200 \mathrm{rpm}$. After reaction time, the resulting mixture was filtered and collected. The solid residue was washed with acetic acid to neutralize ( $\mathrm{pH} 7$ 8) the remaining $\mathrm{NaOH}$ [39]. Many researches have reported that the alkaline treated fibers resulted in high physical and mechanical properties of composites, due to the removal of lignin, hemicellulose, and other compounds on the cellulose surface $[20,21]$. However, obtained CFs showed yellow color (Figure 1(a)), which means that a part of the lignin and other compounds remained on the fiber surface. Therefore, the CFs in this study were also washed with $\mathrm{H}_{2} \mathrm{O}_{2}$ (Figure 1(b)) to remove them from the external surface of CFs, since they could limit the adhesion of CFs with the PP matrix [40, 41]. The CFs were finally dried in an oven for $24 \mathrm{~h}$ for any further use.

2.3. Composite Preparation. CFs with various concentrations $(0,10,20,30,40$, and $50 \mathrm{wt} \%)$ were blended with PP matrix in a plastic mixer (Haake Rheocord 9000, Germany) using a rotor speed of $60 \mathrm{rpm}$ at $185^{\circ} \mathrm{C}$ for $8 \mathrm{~min}$. Then, the obtained mixture was compression molded at $185^{\circ} \mathrm{C}$ for 15 min under $10 \mathrm{MPa}$. The samples were left at room temperature for 5 days before use.

\subsection{Characterization}

2.4.1. Scanning Electron Microscopy (SEM) Observation. The morphology evaluation of rice straw was analyzed using a JEOL 6490 (JEOL, Japan). The morphology evaluation of CFs which were extracted from rice straw using alkaline treatment method and the interfacial bond between CFs and PP matrix in prepared composites and the morphological evaluation of $\mathrm{PP} / \mathrm{CF}$ composites before and after biodegradation were performed using a Hitachi S-4800 scanning electron microscope (Hitachi, Japan).

2.4.2. Water Absorption Test. The water absorption tests of pure $\mathrm{PP}$ and various $\mathrm{PP} / \mathrm{CF}$ composites were carried out following ASTM D 570-99. Rectangular samples were cut with the dimension of $39 \times 10 \times 3 \mathrm{~mm}$, dried at $105^{\circ} \mathrm{C}$ until the weight remained unchanged, cooled to room temperature in a desiccator using silica gel, and immediately weighed with an accuracy of $0.001 \mathrm{~g}$. To investigate the water absorption of $\mathrm{PP} / \mathrm{CF}$ composites, the samples were immersed in the 


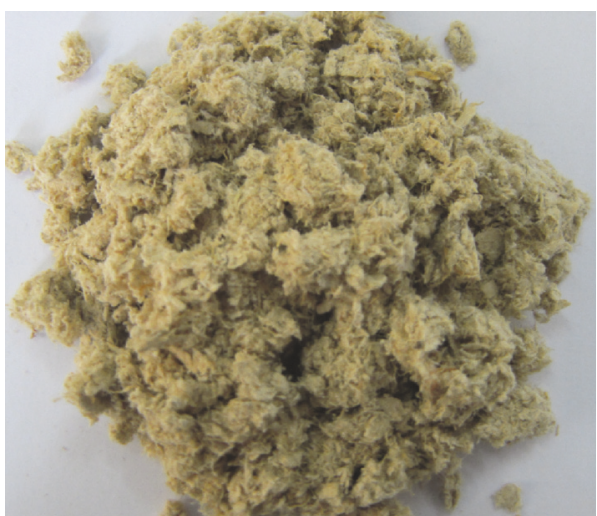

(a)

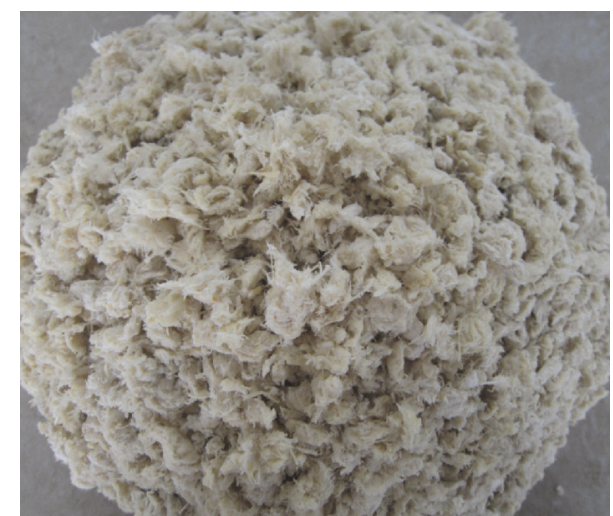

(b)

FIGURE 1: CFs images of before (a) and after (b) being washed with $\mathrm{H}_{2} \mathrm{O}_{2}$.

distilled water for $24 \mathrm{~h}$ at room temperature. Then, the samples were taken, with the excess water on their surface removed using a soft cloth, and weighed. The percentage of water absorption $(W)$ of the samples was calculated using the following:

$$
W(\mathrm{wt} \%)=\frac{W_{2}-W_{1}}{W_{1}} \times 100
$$

$W_{1}$ is weight of the specimen before immersion.

$W_{2}$ is weight of the specimen after immersion.

2.4.3. Thermogravimetric Analysis (TGA). The thermal degradation behavior of the pure $\mathrm{PP}$ and various $\mathrm{PP} / \mathrm{CF}$ composites ( $\mathrm{CFs}$ was washed with $\mathrm{H}_{2} \mathrm{O}_{2}$ ) was analyzed by TGA (SSC/5200 SII Seiko Instruments Inc.). TGA patterns were carried out from room temperature to $650^{\circ} \mathrm{C}$ at a heating rate of $10^{\circ} \mathrm{C} \cdot \mathrm{min}^{-1}$ in a nitrogen atmosphere with a flow rate about $250 \mathrm{ml} \cdot \mathrm{min}^{-1}$.

2.4.4. Mechanical Test. The tensile and flexural tests of pure $\mathrm{PP}$ and $\mathrm{PP} / \mathrm{CFs}$ composites (CFs was washed with $\mathrm{H}_{2} \mathrm{O}_{2}$ ) were carried out following ASTM D 638 and ASTM D 790 standards, respectively. For the tensile strength test, the specimens were cut with dimension of $165 \times 19 \times 3 \mathrm{~mm}$, and crosshead speed was $2 \mathrm{~mm} \cdot \mathrm{min}^{-1}$. For the 4 -point bending flexural strength test, the specimens were cut with dimension of $76 \times 25 \times 3 \mathrm{~mm}$; crosshead motion rate was $2.8 \mathrm{~mm} \cdot \mathrm{min}^{-1}$.

2.4.5. Biodegradation Test. Throwing daily waste in the landfills is the most widely used method of waste disposal today. Landfills are commonly found in developing countries. Therefore, in this study, the rectangular specimens of pure $\mathrm{PP}$ and various $\mathrm{PP} / \mathrm{CFs}$ composites (CFs was washed with $\mathrm{H}_{2} \mathrm{O}_{2}$ ) were cut with dimension of $50 \times 50 \times 3 \mathrm{~mm}$ and then were buried in the soil for 50 days. The degraded samples were washed thoroughly with distilled water at room temperature and then dried at $105^{\circ} \mathrm{C}$ for $24 \mathrm{~h}$. The change in shape of specimens before and after being buried in soil was observed by SEM and weighed.

The percentage weight remaining of biodegraded specimens ( $\left.W_{\text {remaining }}\right)$ was calculated using the specimen weights before $\left(W_{\text {before }}\right)$ and after $\left(W_{\text {after }}\right)$ biodegradation as the following:

$$
W_{\text {remaining }}(\mathrm{wt} \%)=\frac{W_{\text {after }}}{W_{\text {before }}} \times 100 .
$$

\section{Results and Discussion}

3.1. The Morphology and Composition of CFs and PP/CFs Composites. The CFs which were treated by alkaline and then neutralized by acetic acid showed yellow color. However, after being washed with $\mathrm{H}_{2} \mathrm{O}_{2}$, the CFs appeared white, indicating that lignin, hemicellulose, and other compounds which remained on the fiber surface were also removed. The SEM micrographs of alkaline untreated rice straw and $\mathrm{H}_{2} \mathrm{O}_{2}$ washed CFs and PP/CFs 80/20 wt\% composite are shown in Figure 2. Rice straw possessed a block and impurities (Figures 2(a) and 2(b)) but obtained CFs after alkaline treatment and showed clean and rough cylindrical shape with average about $5 \mu \mathrm{m}$ diameter (Figure 2(c)). The removal of lignin, hemicellulose, and wax from the outer cellulose is necessary to strengthen the interfacial bonding between CFs reinforcement and PP matrix $[18,20]$. Figure $2(d)$ is SEM image of representative fractured surface of the PP/CFs $80 / 20 \mathrm{wt} \%$ composite and shows the presence of CFs in the composite.

3.2. Water Absorption. Increasing natural CFs content in the composite materials is desirable because it assists in reducing the cost, protecting the environment, and increasing the modulus of composite materials. The natural CFs are abundant in nature and stiffer than polymer matrix. However, they may not be suitable for several application fields because of their moisture absorption. Therefore, the water absorption is one of the important factors to evaluate properties of material application. To limit the ability of moisture absorption, 


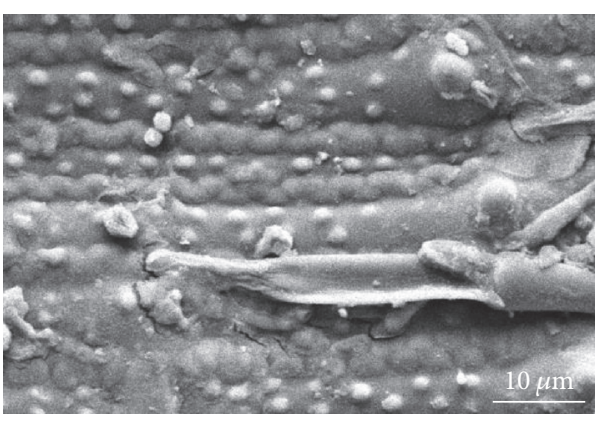

(a)

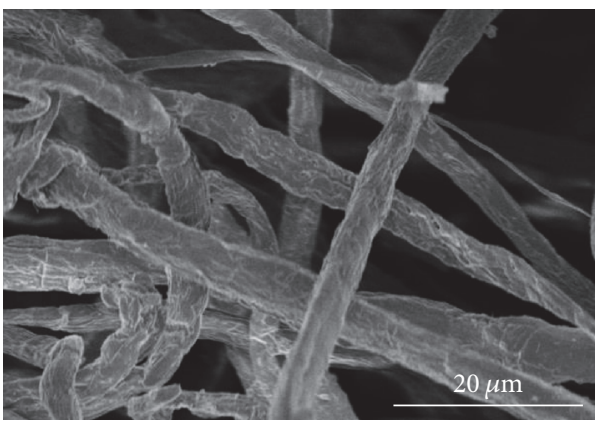

(c)

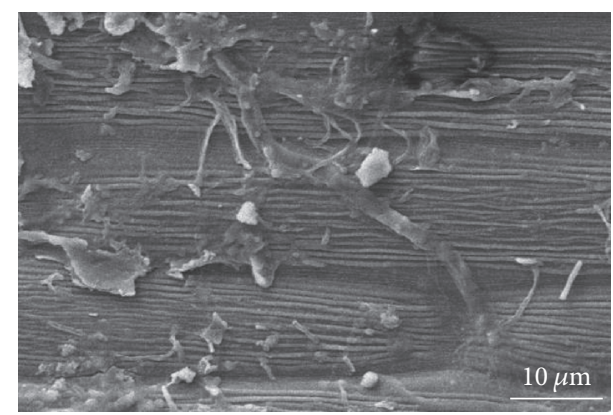

(b)

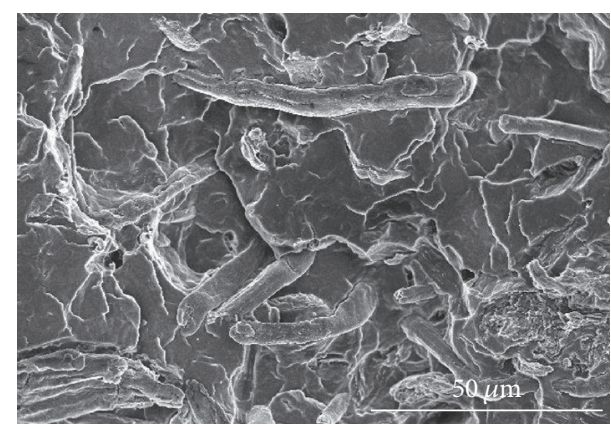

(d)

FIGURE 2: SEM images of (a) exterior surface of rice straw, (b) interior surface of rice straw, (c) CFs after being washed with $\mathrm{H}_{2} \mathrm{O}_{2}$, and (d) representative fractured surface of $\mathrm{PP} / \mathrm{CFs} 80 / 20 \mathrm{wt} \%$ composite.

the surface of natural CFs is modified by various methods including alkaline treatment method. When CFs are treated with alkaline, the hydrophilic - $\mathrm{OH}$ groups in the cellulose structure are converted to hydrophobic -ONa groups [42] as the following reaction:

$$
\text { Cellulose- } \mathrm{OH}+\mathrm{NaOH} \longrightarrow \text { Cellulose- } \mathrm{ONa}+\mathrm{H}_{2} \mathrm{O}
$$

The water absorption of $\mathrm{PP} / \mathrm{CF}$ composites with various ratios of matrix and reinforcement material after immersion in the distilled water for $24 \mathrm{~h}$ at room temperature is evaluated according to (1) and shown in Figure 3. The water absorption was increased with increasing fiber content in the composites. The number of - $\mathrm{OH}$ groups in the cellulose structure, amount of lignin and other compounds, and $\mathrm{NaOH}$ remaining on fibers decide the amount of water absorption. The water absorption of the composites reinforced by $10 \mathrm{wt} \%$ CFs showed 0.69 wt $\%$ when CFs were not washed with $\mathrm{H}_{2} \mathrm{O}_{2}$ but decreased to $0.29 \mathrm{wt} \%$ when CFs were washed with $\mathrm{H}_{2} \mathrm{O}_{2}$. The CFs content increased 20, 30, 40, and $50 \mathrm{wt} \%$, the water absorption of the corresponding composites increased 2.16, 4.10, 5.63, and 6.98 wt\% when not washed with $\mathrm{H}_{2} \mathrm{O}_{2}$ and $0.90,1.72,2.39$, and 2.92 wt $\%$ when washed with $\mathrm{H}_{2} \mathrm{O}_{2}$, respectively. These results demonstrated that the composites reinforced by CFs washed with $\mathrm{H}_{2} \mathrm{O}_{2}$ indicated higher water absorption ability than those not washed with $\mathrm{H}_{2} \mathrm{O}_{2}$. The CFs content increased in the composite materials, which means the number of $\mathrm{OH}$ groups increased, leading to increasing the amount of water absorption [42]. Haque et al. reported that the amount of the water absorption of

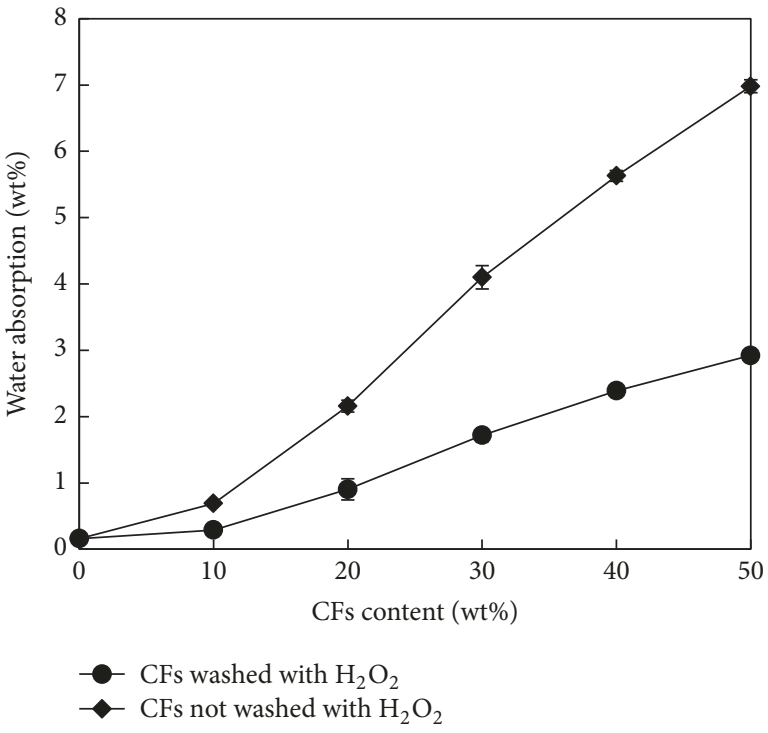

FIGURE 3: The water absorption properties of pure PP and various $\mathrm{PP} / \mathrm{CF}$ s composites with respect to CFs content and washed or not washed with $\mathrm{H}_{2} \mathrm{O}_{2}$ (average value of three tests).

$\mathrm{PP} /$ coir composites was dependent on the type of chemical treatment [42]. The composite materials with untreated coir reinforcement showed the highest water absorption ability, followed by neutral ( $\mathrm{pH} 7)$, acidic ( $\mathrm{pH} 3)$, and alkaline ( $\mathrm{pH}$ 10.5) treated coir fiber reinforced composites, respectively. In 


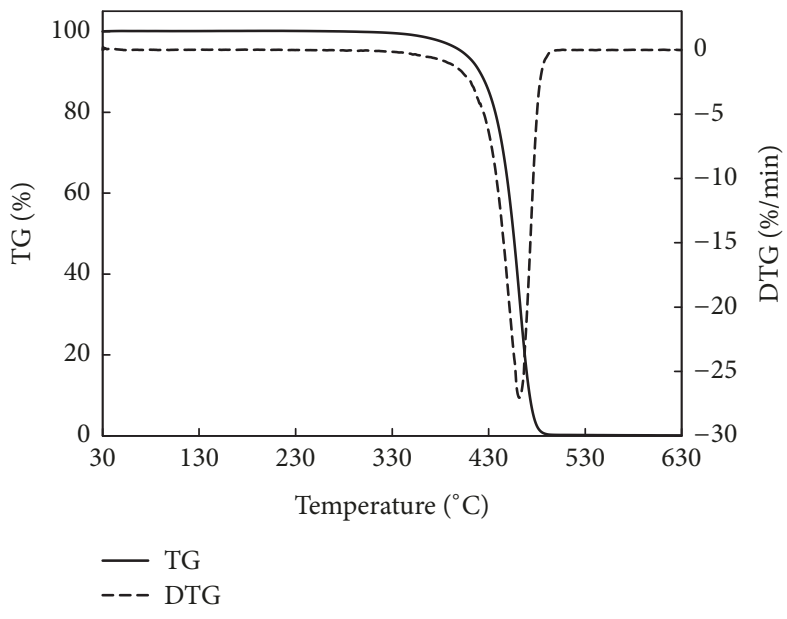

(a)

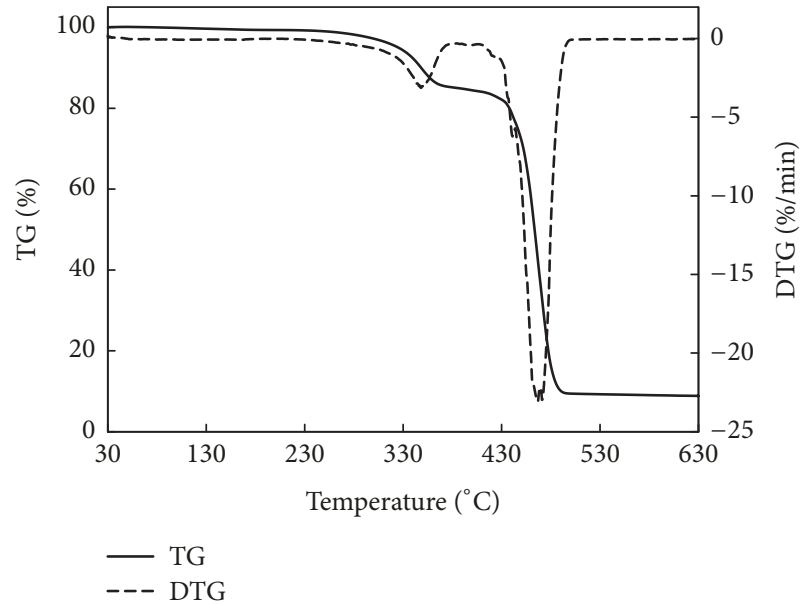

(b)

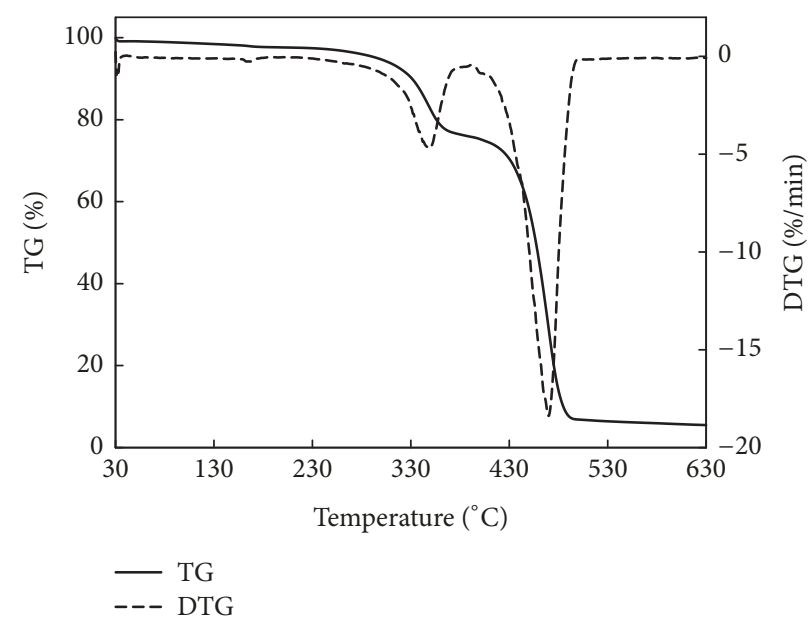

(c)

Figure 4: Representative TG and DTG curves of pure PP (a), PP/CFs 80/20 wt\% (b), and PP/CFs 70/30 wt\% (c) composites at heating rate of $10^{\circ} \mathrm{C} / \mathrm{min}$ under atmosphere at a flow rate of ca. $250 \mathrm{ml} \cdot \mathrm{min}^{-1}$.

this study, the CFs after alkaline treatment were washed with acetic acid to be neutralized and also washed with $\mathrm{H}_{2} \mathrm{O}_{2}$; therefore the remaining $\mathrm{NaOH}$, lignin, hemicellulose, and other compounds were removed. In other words, the water absorption of PP/CFs composites can be controlled by the treatment methods or CFs content.

3.3. Thermal Properties. The thermal property investigation of the polymer composites is necessary to determine the influence of reinforcement materials into polymer matrixes on thermal stability of composites and to confirm any thermal pyrolysis process during composites production. The thermal stability behavior of PP/CFs composites was investigated using thermogravimetric analyzer under nitrogen atmosphere. The representative TGA curves of the pure PP and PP/CFs 80/20 and 70/30 wt\% are shown in Figure 4. The pure PP showed a one-step process of decomposition, while PP/CFs composites clearly showed a two-step process. Decomposition of the CFs reinforcement and PP matrix occurred in the first and second stages, respectively. PP/CFs composites showed intermediary thermal stability between PP matrix and CFs reinforcement [43].

Table 1 shows the weight loss corresponding to the decomposition temperature and decomposition temperature peaks of the pure $\mathrm{PP}$ and various $\mathrm{PP} / \mathrm{CF}$ composites. The pure PP showed one decomposition peak; the PP/CFs composites showed two decomposition peaks corresponding to the peaks of CFs and PP. The thermal stability of composites tends to decrease with increasing CFs content. However, $10 \mathrm{wt} \%$ weight loss temperature of all composites showed high temperature at over $300^{\circ} \mathrm{C}$. Pure PP practically did not lose weight at $400^{\circ} \mathrm{C}$; however its weight loss occurred rapidly from $462^{\circ} \mathrm{C}$, resulting in minimum residue. The saturated and unsaturated carbon atoms in PP were degraded at about $460^{\circ} \mathrm{C}$, which was higher than that for CFs.

3.4. Mechanical Properties. Mechanical properties of the pure $\mathrm{PP}$ and various $\mathrm{PP} / \mathrm{CFs}$ composites were investigated for tensile strength, Young's modulus, flexural properties, and elongation at break. Figures 4 and 5 and Table 2 showed 
TABLE 1: Thermal properties of pure PP and various PP/CFs composites.

\begin{tabular}{|c|c|c|c|c|c|}
\hline \multirow{2}{*}{ Sample } & \multicolumn{3}{|c|}{ Weight loss temperature $\left({ }^{\circ} \mathrm{C}\right)$} & \multirow{2}{*}{\multicolumn{2}{|c|}{$\begin{array}{c}\text { Decomposition temperature } \\
\text { peak }\left({ }^{\circ} \mathrm{C}\right)\end{array}$}} \\
\hline & $10 \mathrm{wt} \%$ & $20 \mathrm{wt} \%$ & $30 \mathrm{wt} \%$ & & \\
\hline Pure PP & 420 & 437 & 445 & - & 462 \\
\hline PP/CFs 90/10 wt\% & 364 & 439 & 455 & 350 & 465 \\
\hline $\mathrm{PP} / \mathrm{CFs} 80 / 20 \mathrm{wt} \%$ & 348 & 438 & 453 & 348 & 467 \\
\hline $\mathrm{PP} / \mathrm{CFs} 70 / 30 \mathrm{wt} \%$ & 331 & 355 & 431 & 348 & 470 \\
\hline $\mathrm{PP} / \mathrm{CFs} 60 / 40 \mathrm{wt} \%$ & 320 & 332 & 418 & 347 & 471 \\
\hline PP/CFs 50/50 wt $\%$ & 306 & 316 & 398 & 346 & 468 \\
\hline
\end{tabular}

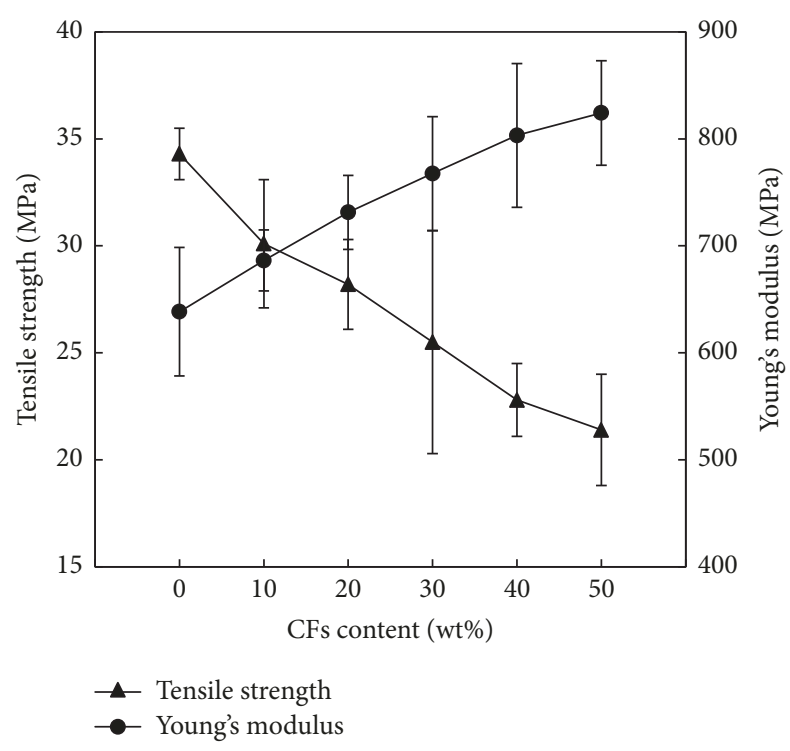

Figure 5: Effect of CFs content on the tensile properties of PP/CFs composites (average value of six tests).

mechanical properties of pure PP and various PP/CFs composites which were averaging results of 6 specimens for each green composite. The tensile strength of PP/CFs composites was decreased, whereas their Young's modulus was increased with increasing CFs content, as expected (Figure 5). A similar behavior was reported for jute strands [44], wood floor and olive stone flour [45], Thespesia lampas fibers [46], and rice husk [47] for PP matrix composites. The tensile strength depends on the weakest part of the composite materials and further interfacial interaction between PP matrix and CFs is weak, leading to the decrease in the tensile strength of $\mathrm{PP} / \mathrm{CF}$ s composites with increasing CFs content. However, the flexural properties of PP were improved by blending with CFs up to $50 \mathrm{wt} \%$ content (Figure 6). Improvement of the Young's modulus and flexural properties is expected to be due to the high stiffness of the CFs compared to the PP matrix. In addition, partially separated microspaces which were created during tensile loading, obstructed stress propagation between CFs and PP matrix, hence the obstruction degree increased with increasing CFs content, leading to the increase in the stiffness [38]. The elongation at break of pure PP showed $57.5 \%$, but it was significantly decreased with the loading

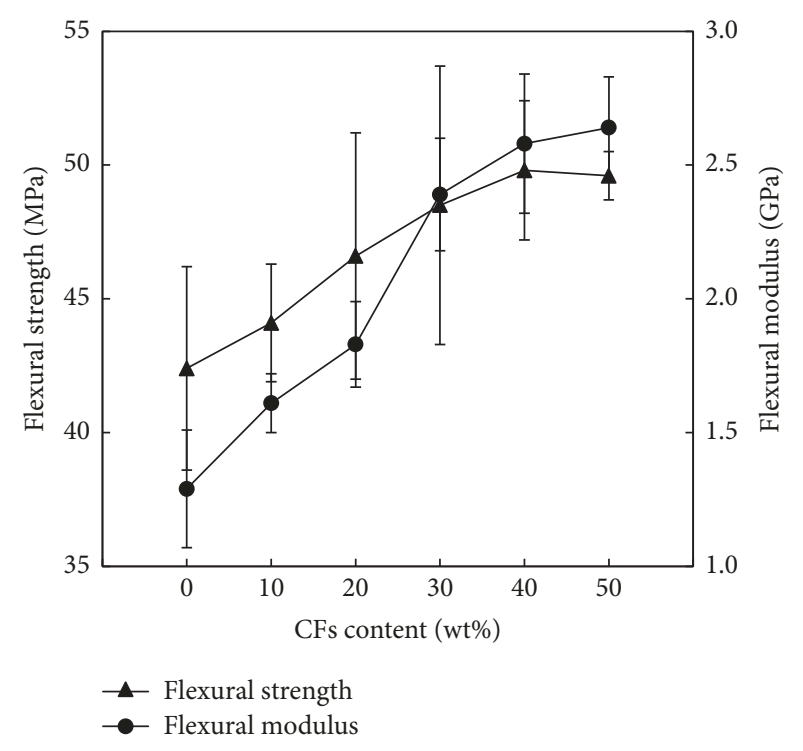

FIGURE 6: Effect of CFs content on the flexural properties of PP/CFs composites (average value of six tests).

level of CFs (Table 2). The poor elongation of the PP/CFs composites is probably due to the weak interactions between PP matrix and CFs, which generates stress concentration points and agglomeration. On the other hand, this result can prove that CFs improved the stiffness of composite materials.

3.5. Biodegradation. Plastics including PP which are synthesized from petroleum products are often burnt or buried after use. The burning of plastic wastes releases gases and chemicals into the air, leading to smog, acid rain, and toxic air pollution. Most of these plastic wastes show no degradability and accumulate in the environment when being buried, considerably increasing environmental pollution. In recent years, to reduce the burden on the environment, the composites between synthetic plastics composite with natural fibers have attracted much attention. There are many reports on these composite materials. However, most of them have reported their thermal and mechanical properties, without mentioning their biodegradability. In this study, we evaluate the biodegradability of composite of PP and CFs which were extracted from rice straw using alkaline treatment method and washed with $\mathrm{H}_{2} \mathrm{O}_{2}$. The samples after being buried in the soil for a certain period of time were washed, dried, 
TABLE 2: Mechanical properties of pure PP and various PP/CFs composites.

\begin{tabular}{lccccc}
\hline Sample & $\begin{array}{c}\text { Tensile } \\
\text { strength } \\
(\mathrm{MPa})\end{array}$ & $\begin{array}{c}\text { Young's } \\
\text { modulus } \\
(\mathrm{MPa})\end{array}$ & $\begin{array}{c}\text { Elongation at } \\
\text { break } \\
(\%)\end{array}$ & $\begin{array}{c}\text { Flexural } \\
\text { strength } \\
(\mathrm{MPa})\end{array}$ & $\begin{array}{c}\text { Flexural } \\
\text { modulus } \\
(\mathrm{GPa})\end{array}$ \\
\hline Pure PP & $34.3 \pm 1.2$ & $638.5 \pm 60.1$ & $57.5 \pm 5.6$ & $42.4 \pm 12.6$ & $1.29 \pm 0.22$ \\
PP/CFs 90/10 wt\% & $30.1 \pm 3.0$ & $686.4 \pm 28.5$ & $15.2 \pm 1.2$ & $10.9 \pm 0.9$ & $46.6 \pm 4.6$ \\
PP/CFs 80/20 wt\% & $28.1 \pm 2.1$ & $731.3 \pm 34.6$ & $8.0 \pm 2.1$ & $48.5 \pm 5.2$ & $1.61 \pm 0.11$ \\
PP/CFs 70/30 wt\% & $25.5 \pm 5.2$ & $767.6 \pm 53.2$ & $6.2 \pm 0.8$ & $49.8 \pm 2.6$ & $2.39 \pm 0.21$ \\
PP/CFs 60/40 wt\% & $22.8 \pm 1.7$ & $803.2 \pm 67.2$ & $4.5 \pm 1.1$ & $49.6 \pm 0.9$ & $2.58 \pm 0.26$ \\
PP/CFs 50/50 wt\% & $21.4 \pm 2.6$ & $824.2 \pm 48.8$ & & & $2.64 \pm 0.19$ \\
\hline
\end{tabular}

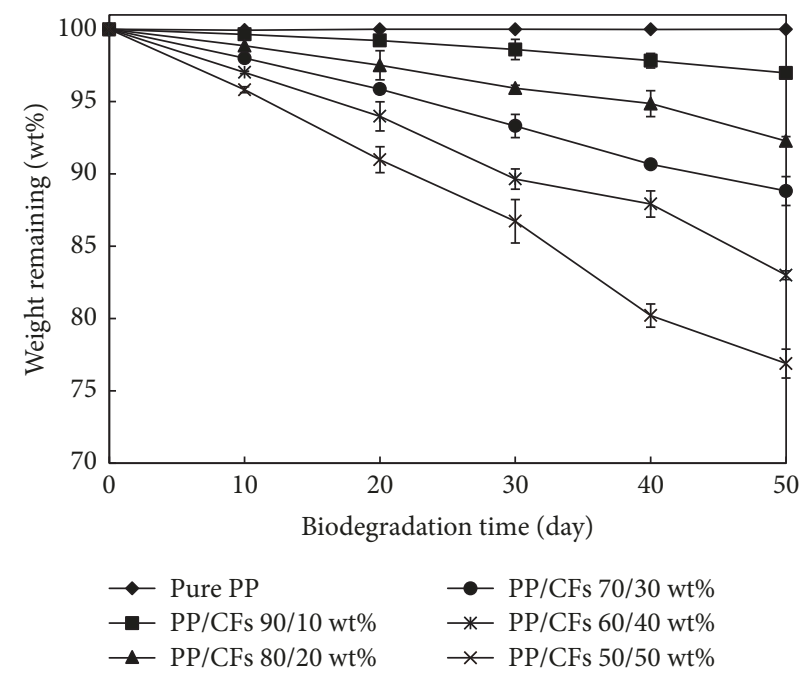

FIGURE 7: Biodegradation behavior of pure PP and various PP/CFs composites with respect to CFs content (average value of three tests).

weighted, and evaluated for the biodegradability according to (2). Figure 7 shows the weight remaining percentage of the pure $\mathrm{PP}$ and $\mathrm{PP} / \mathrm{CF}$ composites with $90 / 10,80 / 20,70 / 30$, $60 / 40$, and 50/50 wt\%. As expected, the weight of the pure PP was not changed after being buried in the soil for 50 days; in other words, pure PP was not degraded. However, the remaining weight of $\mathrm{PP} / \mathrm{CF}$ s composites decreased with the burying time in the soil and their degradation rate increased with increasing CFs content. After 50 days being buried in the soil, the remaining weight percentage of $\mathrm{PP} / \mathrm{CF}$ composites with $90 / 10,80 / 20,70 / 30,60 / 40$, and $50 / 50$ wt\% was 96.98 , $92.28,88.82,83.00$, and $76.89 \mathrm{wt} \%$, respectively.

The SEM observation provided further information on the morphology of the representative PP/CFs 80/20wt\% composite and the pure PP during biodegradation (Figure 8). Before being buried in the soil, both pure PP and composite displayed smooth surfaces (Figure 8(b)). After being buried in the soil for 50 days, the surface of the pure PP did not show deformation and remained as a flat surface without holes (Figure 8(a)), whereas that of the PP/CFs $80 / 20 \mathrm{wt} \%$ composite showed the existence of many holes (Figure 8(c)). Moreover, the fractured surface of the pure PP was not changed after being buried in soil for 50 days (Figures $8(\mathrm{~d}$ ) and $8(\mathrm{e}))$, which means PP was not degraded. However, the various CFs in $\mathrm{PP} / \mathrm{CFs} 80 / 20 \mathrm{wt} \%$ composite were observed on the fractured surface before being buried in the soil (Figure 2(d)), but they were biodegraded with many holes formed after 50-day burial in soil (Figure 8(f)). According to this research, environmental degradation of the PP/CFs composites was affected by natural factors, including not only rainwater and underground water but also microbial activities.

\section{Conclusions}

Green composite materials from PP and various content of CFs extracted from rice straw were successfully prepared by a simple melt blending method. The water absorption of $\mathrm{PP} / \mathrm{CF}$ composites could be controlled by CFs content and treatment methods. The thermal stability of PP was decreased with the loading level of CFs, due to the low thermal properties of CFs, but their $10 \%$ weight loss temperature showed to be over $300^{\circ} \mathrm{C}$. Young's modulus flexural properties of PP were improved by being blended with CFs; in other words, CFs improved the stiffness of composites. Particularly, PP showed no biodegradability, whereas PP/CFs composites showed that the opposite and their weight loss from 3.02 to 23. $11 \mathrm{wt} \%$ depended on the CFs content after being buried in soil for 50 days. These results proved that the composites materials may be applied to various environmental fields. This 


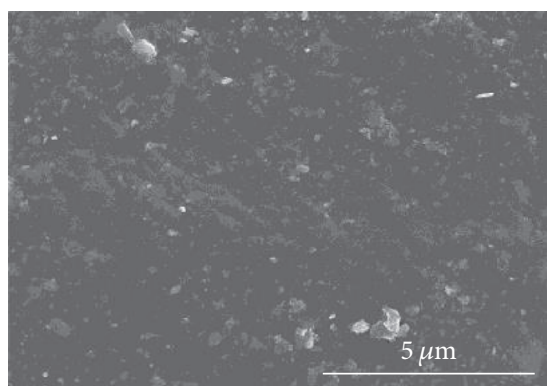

(a)

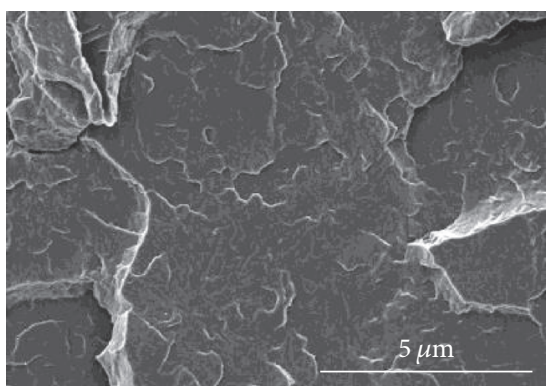

(d)

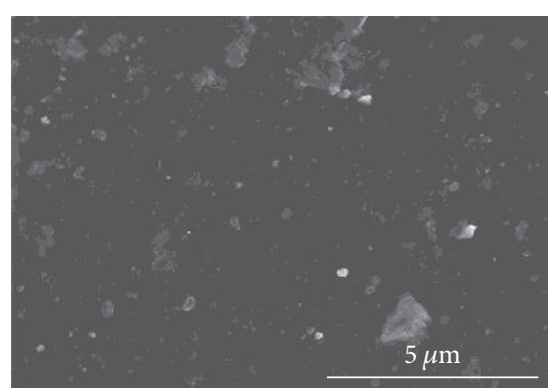

(b)

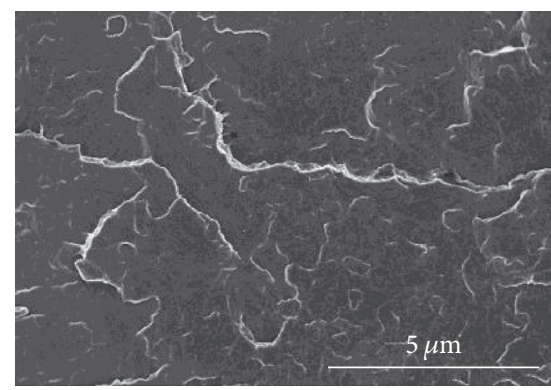

(e)

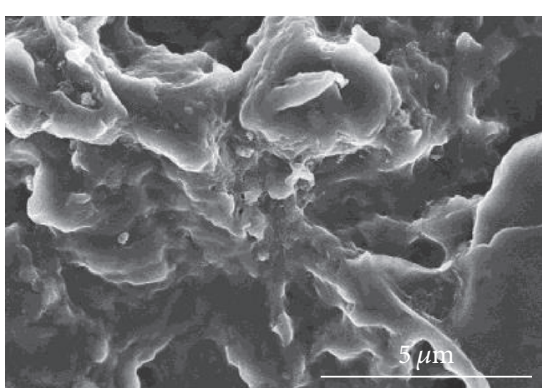

(c)

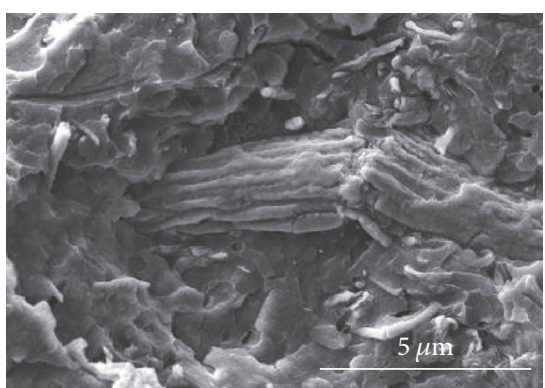

(f)

FIGURE 8: Representative biodegradation behavior in SEM images of the surface of pure PP for 50 days (a), PP/CFs $80 / 20$ wt $\%$ composite for 0 days (b) and 50 days (c), the fractured surface of pure PP for 0 days (d) and 50 days (e), and PP/CFs 80/20 wt\% composite for 50 days (f).

study is expected to contribute to environmental protection and solving the problem of wasting resources.

\section{Conflicts of Interest}

The authors declare that they have no conflicts of interest.

\section{Acknowledgments}

This research was supported by Vietnam's National Project DTDL.CN-07/15.

\section{References}

[1] Z. Demjen, B. Pukánszky, and J. Nagy, "Evaluation of interfacial interaction in polypropylene/surface treated $\mathrm{CaCO} 3$ composites," Composites Part A: Applied Science and Manufacturing, vol. 29, no. 3, pp. 323-329, 1998.

[2] A. P. Mathew, K. Oksman, and M. Sain, "Mechanical properties of biodegradable composites from poly lactic acid (PLA) and microcrystalline cellulose (MCC)," Journal of Applied Polymer Science, vol. 97, no. 5, pp. 2014-2025, 2005.

[3] A. Terenzi, J. M. Kenny, and S. E. Barbosa, "Natural fiber suspensions in thermoplastic polymers. I. analysis of fiber damage during processing," Journal of Applied Polymer Science, vol. 103, no. 4, pp. 2501-2506, 2007.

[4] S. Misha, S. Mat, M. H. Ruslan, E. Salleh, and K. Sopian, "Performance of a solar assisted solid desiccant dryer for kenaf core fiber drying under low solar radiation," Solar Energy, vol. 112, pp. 194-204, 2015.

[5] C. M. Clemons and D. F. Caulfield, Functional fillers for plastics. Natural fibers, Wiley-VCH, Germany, 2005.
[6] S. J. J. Lips, G. M. Iñiguez de Heredia, R. G. M. Op den Kamp, and J. E. G. van Dam, "Water absorption characteristics of kenaf core to use as animal bedding material," Industrial Crops and Products, vol. 29, no. 1, pp. 73-79, 2009.

[7] W. L. E. Magalhaes, S. A. Pianaro, C. J. F. Granado, and K. G. Satyanarayana, "Preparation and characterization of polypropylene/heart-of-peach palm sheath composite," Journal of Applied Polymer Science, vol. 127, no. 2, pp. 1285-1294, 2013.

[8] M. A. Binhussain and M. M. El-Tonsy, "Palm leave and plastic waste wood composite for out-door structures," Construction and Building Materials, vol. 47, pp. 1431-1435, 2013.

[9] S. G. Bajwa, D. S. Bajwa, G. Holt, T. Coffelt, and F. Nakayama, "Properties of thermoplastic composites with cotton and guayule biomass residues as fiber fillers," Industrial Crops and Products, vol. 33, no. 3, pp. 747-755, 2011.

[10] P. Darabi, J. Gril, M. F. Thevenon, A. N. Karimi, and M. Azadfalah, "Evaluation of high density polyethylene composite filled with bagasse after accelerated weathering followed by biodegradation," Bioresources, vol. 7, no. 4, pp. 5258-5267, 2012.

[11] A. Kaymakci, N. Ayrilmis, and T. Gulec, "Surface properties and hardness of polypropylene composites filled with sunflower stalk flour," Bioresources, vol. 8, no. 1, pp. 592-602, 2013.

[12] N. Amir, K. A. Z. Abidin, and F. B. M. Shiri, "Effects of Fibre Configuration on Mechanical Properties of Banana Fibre/ PP/MAPP Natural Fibre Reinforced Polymer Composite," in Proceedings of the Advances in Material and Processing Technologies Conference, AMPT 2017, pp. 573-580, India, December 2017.

[13] K. G. Satyanarayana, G. G. C. Arizaga, and F. Wypych, "Biodegradable composites based on lignocellulosic fibers-an overview," Progress in Polymer Science, vol. 34, no. 9, pp. 9821021, 2009. 
[14] P. Wambua, J. Ivens, and I. Verpoest, "Natural fibres: can they replace glass in fibre reinforced plastics?" Composites Science and Technology, vol. 63, no. 9, pp. 1259-1264, 2003.

[15] T. Alsaeed, B. F. Yousif, and H. Ku, "The potential of using date palm fibres as reinforcement for polymeric composites," Materials \& Design, vol. 43, pp. 177-184, 2013.

[16] M. S. Islam, J. S. Church, and M. Miao, "Effect of removing polypropylene fibre surface finishes on mechanical performance of kenaf/polypropylene composites," Composites Part A: Applied Science and Manufacturing, vol. 42, no. 11, pp. 16871693, 2011.

[17] M. Brahmakumar, C. Pavithran, and R. M. Pillai, "Coconut fibre reinforced polyethylene composites: effect of natural waxy surface layer of the fibre on fibre/matrix interfacial bonding and strength of composites," Composites Science and Technology, vol. 65, no. 3-4, pp. 563-569, 2005.

[18] M. N. Akhtar, A. B. Sulong, M. K. F. Radzi et al., "Influence of alkaline treatment and fiber loading on the physical and mechanical properties of kenaf/polypropylene composites for variety of applications," Progress in Natural Science: Materials International, vol. 26, no. 6, pp. 657-664, 2016.

[19] N. Kumar, S. Mireja, V. Khandelwal, B. Arun, and G. Manik, "Light-weight high-strength hollow glass microspheres and bamboo fiber based hybrid polypropylene composite: A strength analysis and morphological study," Composites Part B: Engineering, vol. 109, pp. 277-285, 2017.

[20] T. Sullins, S. Pillay, A. Komus, and H. Ning, "Hemp fiber reinforced polypropylene composites: The effects of material treatments," Composites Part B: Engineering, vol. 114, pp. 15-22, 2017.

[21] P. Krishnaiah, C. T. Ratnam, and S. Manickam, "Enhancements in crystallinity, thermal stability, tensile modulus and strength of sisal fibres and their PP composites induced by the synergistic effects of alkali and high intensity ultrasound (HIU) treatments," Ultrasonics Sonochemistry, vol. 34, pp. 729-742, 2017.

[22] J.-C. Zarges, D. Minkley, M. Feldmann, and H.-P. Heim, "Fracture toughness of injection molded, man-made cellulose fiber reinforced polypropylene," Composites Part A: Applied Science and Manufacturing, vol. 98, pp. 147-158, 2017.

[23] Y. Habibi, W. K. El-Zawawy, M. M. Ibrahim, and A. Dufresne, "Processing and characterization of reinforced polyethylene composites made with lignocellulosic fibers from Egyptian agro-industrial residues," Composites Science and Technology, vol. 68, no. 7-8, pp. 1877-1885, 2008.

[24] X. Li, L. G. Tabil, and S. Panigrahi, "Chemical treatments of natural fiber for use in natural fiber-reinforced composites: a review," Journal of Polymers and the Environment, vol. 15, no. 1, pp. 25-33, 2007.

[25] S. Kalia, B. S. Kaith, and I. Kaur, "Pretreatments of natural fibers and their application as reinforcing material in polymer composites-a review," Polymer Engineering \& Science, vol. 49, no. 7, pp. 1253-1272, 2009.

[26] N. Suardana, Y. Piao, and J. K. Lim, "Mechanical properties of HEMP fibers and HEMP/PP composites: Effects of chemical surface treatment," Materials Physics and Mechanics, vol. 11, no. 1, pp. 1-8, 2011.

[27] D. Ray, B. K. Sarkar, A. K. Rana, and N. R. Bose, "Effect of alkali treated jute fibres on composite properties," Bulletin of Materials Science, vol. 24, no. 2, pp. 129-135, 2001.

[28] S. Panthapulakkal, A. Zereshkian, and M. Sain, "Preparation and characterization of wheat straw fibers for reinforcing application in injection molded thermoplastic composites," Bioresource Technology, vol. 97, no. 2, pp. 265-272, 2006.

[29] P. R. Hornsby, E. Hinrichsen, and K. Tarverdi, "Preparation and properties of polypropylene composites reinforced with wheat and flax straw fibres: Part I Fibre characterization," Journal of Materials Science, vol. 32, no. 2, pp. 443-449, 1997.

[30] P. R. Hornsby, E. Hinrichsen, and K. Tarverdi, "Preparation and properties of polypropylene composites reinforced with wheat and flax straw fibres: part II Analysis of composite microstructure and mechanical properties," Journal of Materials Science, vol. 32, no. 4, pp. 1009-1015, 1997.

[31] Y. Zou, S. Huda, and Y. Yang, "Lightweight composites from long wheat straw and polypropylene web," Bioresource Technology, vol. 101, no. 6, pp. 2026-2033, 2010.

[32] FAO Ric Market Monitor, vol. XX, no. 2, uly 2017.

[33] R. Dungani, M. Karina, Subyakto, A. Sulaeman, D. Hermawan, and A. Hadiyane, "Agricultural waste fibers towards sustainability and advanced utilization: A review," Asian Journal of Plant Sciences, vol. 15, no. 1-2, pp. 42-55, 2016.

[34] H. Kono, "Cationic flocculants derived from native cellulose: Preparation, biodegradability, and removal of dyes in aqueous solution," Resource-Efficient Technologies, vol. 3, no. 1, pp. 55-63, 2017.

[35] "Rice straw and Wheat straw," in Potetial feedstocks for the Biobased Economy, 2013.

[36] R. R. Zaky, M. M. Hessien, A. A. El-Midany, M. H. Khedr, E. A. Abdel-Aal, and K. A. El-Barawy, "Preparation of silica nanoparticles from semi-burned rice straw ash," Powder Technology, vol. 185, no. 1, pp. 31-35, 2008.

[37] R. T. Rashad, "Separation of some rice straw components and studying their effect on some hydro-physical properties of two different soils," Journal of Environmental Chemical Engineering (JECE), vol. 1, no. 4, pp. 728-735, 2013.

[38] R. Khandanlou, M. B. Ahmad, K. Shameli, and K. Kalantari, "Synthesis and characterization of rice straw $/ \mathrm{Fe}_{3} \mathrm{O}_{4}$ nanocomposites by a quick precipitation method," Molecules, vol. 18, no. 6, pp. 6597-6607, 2013.

[39] M. Le Troedec, D. Sedan, C. Peyratout et al., "Influence of various chemical treatments on the composition and structure of hemp fibres," Composites Part A: Applied Science and Manufacturing, vol. 39, no. 3, pp. 514-522, 2008.

[40] H. Ku, H. Wang, N. Pattarachaiyakoop, and M. Trada, "A review on the tensile properties of natural fiber reinforced polymer composites," Composites Part B: Engineering, vol. 42, no. 4, pp. 856-873, 2011.

[41] M. Rokbi, "Effect of chemical treatment on flexure properties of natural fiber-reinforced polyester composite," Procedia Engineering, vol. 10, pp. 2092-2097, 2011.

[42] M. M. Haque, M. E. Ali, M. Hasan, M. N. Islam, and H. Kim, "Chemical treatment of coir fiber reinforced polypropylene composites," Industrial \& Engineering Chemistry Research, vol. 51, no. 10, pp. 3958-3965, 2012.

[43] S. M. Luz, J. Del Tio, G. J. M. Rocha, A. R. Gonçalves, and A. P. Del'Arco Jr., "Cellulose and cellulignin from sugarcane bagasse reinforced polypropylene composites: effect of acetylation on mechanical and thermal properties," Composites Part A: Applied Science and Manufacturing, vol. 39, no. 9, pp. 1362-1369, 2008.

[44] J. P. Lopez, S. Boufi, N. E. El Mansouri, P. Mutjé, and F. Vilaseca, "PP composites based on mechanical pulp, deinked newspaper and jute strands: A comparative study," Composites Part B: Engineering, vol. 43, no. 8, pp. 3453-3461, 2012. 
[45] I. Naghmouchi, F. X. Espinach, P. Mutjé, and S. Boufi, "Polypropylene composites based on lignocellulosic fillers: how the filler morphology affects the composite properties," Materials and Corrosion, vol. 65, no. 1, pp. 454-461, 2015.

[46] B. Ashok, K. O. Reddy, K. Madhukar, J. Cai, L. Zhang, and A. V. Rajulu, "Properties of cellulose/Thespesia lampas short fibers bio-composite films," Carbohydrate Polymers, vol. 127, pp. 110115, 2015.

[47] S.-K. Yeh, C.-C. Hsieh, H.-C. Chang, C. C. C. Yen, and Y.C. Chang, "Synergistic effect of coupling agents and fiber treatments on mechanical properties and moisture absorption of polypropylene-rice husk composites and their foam," Composites Part A: Applied Science and Manufacturing, vol. 68, pp. 313-322, 2015. 


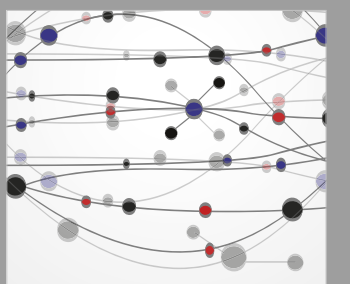

The Scientific World Journal
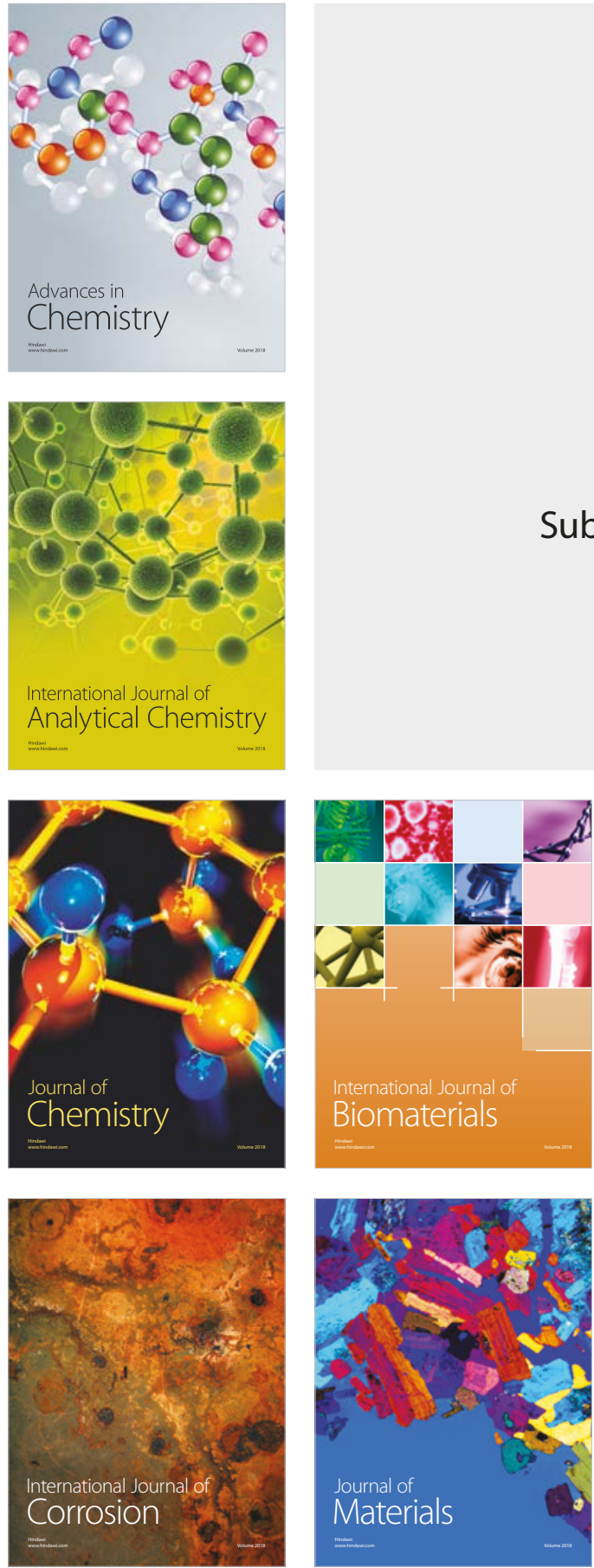

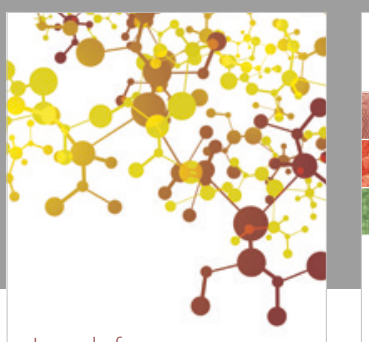

Journal of

Applied Chemistry
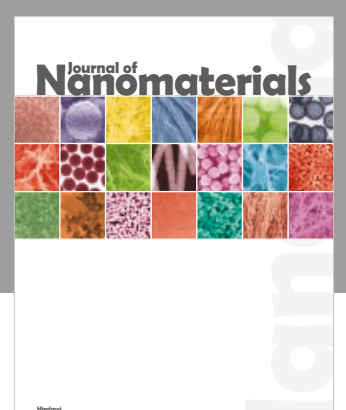

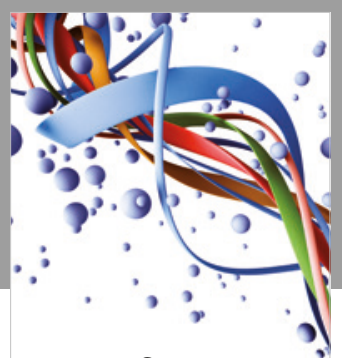

Scientifica

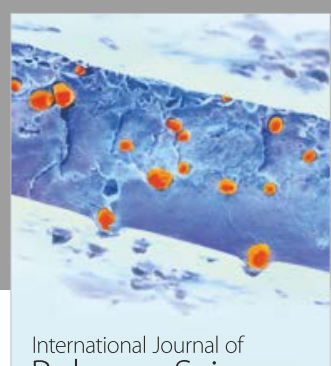

Polymer Science

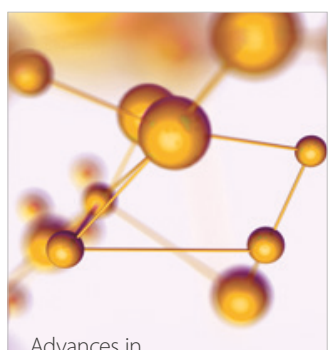

Physical Chemistry
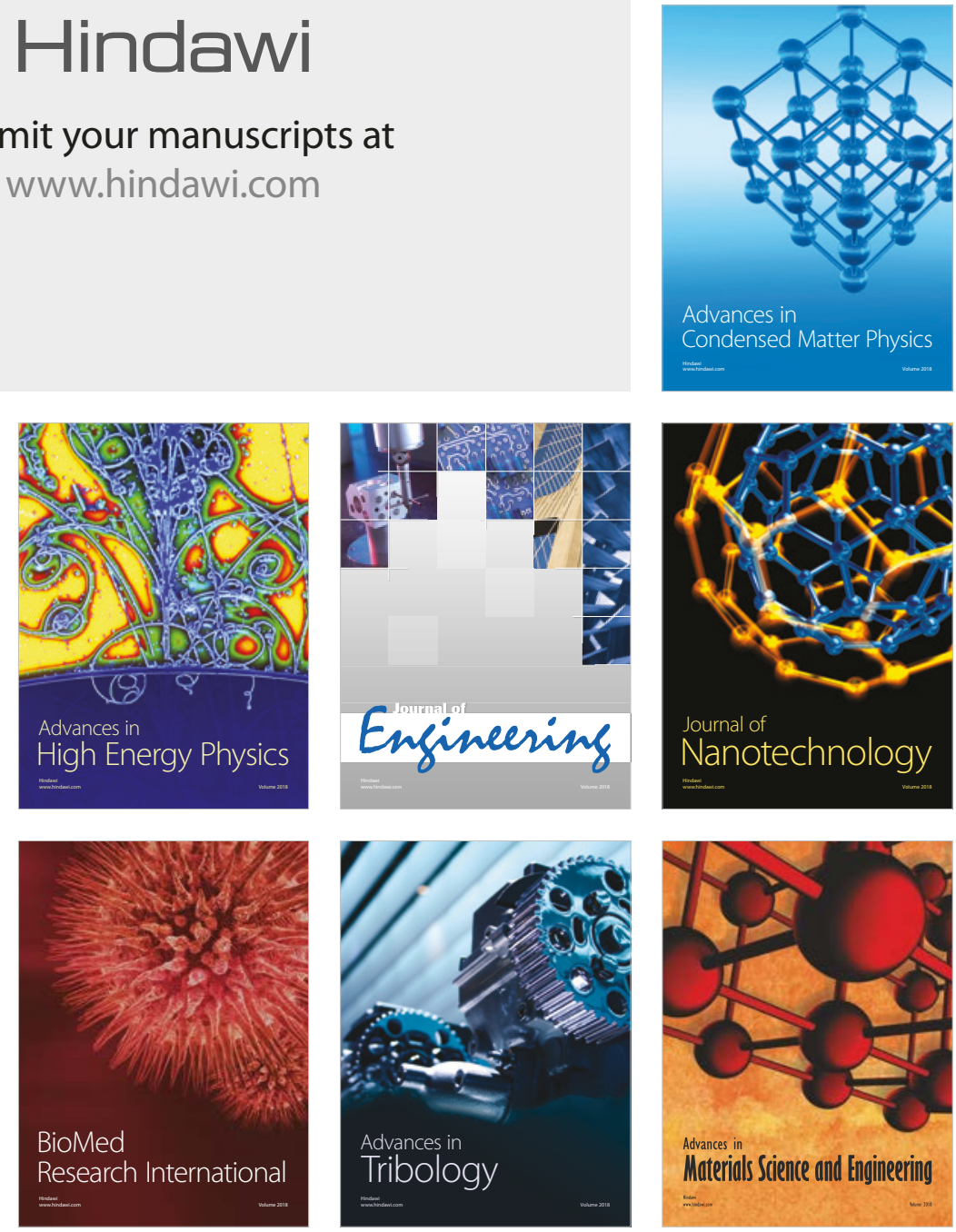